\title{
Population models for threshold-based control of Tetranychus urticae in small-scale Kenyan tomato fields and for evaluating weather and host plant species effects
}

\author{
Markus Knapp · Ibrahima Sarr • Gianni Gilioli • \\ Johann Baumgärtner
}

Received: 11 April 2006/ Accepted: 3 July 2006/ Published online: 3 August 2006

(C) Springer Science+Business Media B.V. 2006

\begin{abstract}
The spatial distribution of motile life stages of the two-spotted spider mite Tetranychus urticae Koch in Kenyan small-scale tomato fields was described by Taylor's power law and an enumerative sampling plan was designed for research purposes. The exponential increase of $T$. urticae populations during three growing seasons permits the development and use of a simple exponential model for the design of a threshold-based chemical control system. For this purpose, a critical threshold of 440 motile mites per sample unit at the end of the growing season (12 weeks after transplanting) was translated into a proportion of 0.83 infested units in sample 3 , i.e. five weeks after transplanting. A sequential binomial sampling plan with respect to the proportion of 0.83 , five weeks after transplanting, was designed. The exponential model was extended to account for the influence of weather and host plant species. Model development and parameter estimation were based on three data sets (Kenyan tomato fields, Italian and Californian strawberry fields). The model satisfactorily predicted a positive influence on growth rates by $(i)$ changing the host plant from tomato to strawberry, and (ii) temperature, while a negative effect resulted from (iii) rainfall; both (ii) and (iii) are controlled by temperature-rainfall interactions. In contrast, the estimated parameter values did not satisfactorily describe the expected responses at specific temperature and rainfall values. Nevertheless, the model allowed the rating of host plant species in the field. A fourth data set from Swiss apple orchards was used to test the model, and population build-up on the apple host plant appeared to be higher than on tomatoes but lower than on strawberry.
\end{abstract}

Keywords Tetranychus urticae Population model $\cdot$ Threshold-based control · Weather $\cdot$ Host plants

M. Knapp $(\bowtie) \cdot$ I. Sarr · J. Baumgärtner

International Centre of Insect Physiology and Ecology (ICIPE), P.O. Box 30772-00100,

Nairobi, Kenya

e-mail: mknapp@icipe.org

G. Gilioli

Dipartimento GESAF, Università Mediterranea di Reggio Calabria, Piazza S. Francesco da Sales, 4 - 89061 Gallina di Reggio di Calabria, Italy 


\section{Introduction}

In many parts of the world, the two-spotted spider mite Tetranychus urticae Koch has become an important pest of greenhouse and field tomatoes (Abdel-Shaheed et al. 1971; Hussey and Scopes 1985; Nihoul et al. 1991; Bezert 1999). Tetranychus urticae has been reported to cause damage on tomato in many Sub-Saharan African countries including South Africa (Daiber 1996), Zambia (Jensen and Mingochi 1988), Zimbabwe (Sibanda et al. 2000) and semi-arid areas in Kenya (Varela et al. 2003). While many studies have been undertaken on spatial and temporal distribution patterns as well as damage levels in greenhouse grown tomatoes (Hussey and Scopes 1985; Stacey et al. 1985; Nihoul et al. 1991; Nihoul 1993a, b; Kielkiewicz 1996), little is known about field-grown tomatoes (Abdel-Shaheed et al. 1971; Bezert 1999). Small-scale Kenyan tomato growers generally observe an exponential increase in $T$. urticae population densities until the time of harvest and exclusively rely on synthetic acaricides to control the pest. The frequent applications of acaricides are justified on empirical grounds at best without due consideration of ecological as well as economic criteria. This is because the information on interactions between crop yield formation and $T$. urticae population dynamics is not sufficient for specifying economic injury levels. The availability of such information would allow the development of threshold-based control strategies where the efficiency of chemical control is increased by taking decisions with respect to a critical threshold. Threshold-based control relies among others, on efficient estimation of population densities or proportions of infested sampling units at specified sampling dates.

Rather than unilaterally relying on chemical control, Integrated Pest Management (IPM) refers to an integrated system of compatible control techniques that are applied under consideration of ecological and economic components, the latter consisting of knowledge on control costs and yield loss information. Often, the necessary ecological understanding is sought by following population structures through time as well as space and relying on quantitative methods to explain the observed changes (see e.g. Kapatos and Stratopoulou 1990; Gutierrez 1996). For the study of the spatio-temporal dynamics sampling plans are indispensable to obtain reliable estimates of population parameters.

Population changes result from demographic processes including fecundity, mortality, immigration and emigration. The dynamics of spider mite populations are often characterized by high fluctuations over time and space, and mite outbreaks have frequently been associated with the combination of hot and dry weather conditions as well as the absence of predators and the nutritional quality of host plants (Baumgärtner et al. 1988). Meteorological parameters including temperature and rainfall may have direct physiological and mechanical effects on arthropods or indirect effects resulting from changes in the quality of the host plants. In the following we refer to meteorological parameters as weather for reasons of simplicity. The quality of the host plant for spider mites is influenced by plant nutrition as well as by species. To separate the influence of weather factors and host plant effects and their combined effects on population development, and to design appropriate integrated control strategies, the development and use of population models is considered as indispensable. Many studies on host plant suitability have been carried out under controlled conditions with mite cohorts. This environment restricts the movement of mites. To be able to separate host plant effects from other factors 
impinging on demographic processes and affecting population dynamics, these laboratory studies should be complemented with fieldwork.

Threshold-based chemical control is an integral part of IPM systems. The critical threshold is determined on the basis of the pest population dynamics and once it is passed, pesticides are applied to prevent populations from reaching economically significant levels. In the case of $T$. urticae in Kenyan tomato fields, the observed exponential increase in $T$. urticae population abundance provides an opportunity for developing an easy to use threshold-based control system. From a methodological standpoint, we rely on Rabbinge and Rijsdijk (1983) who observed an exponential infestation pattern of cereal aphids and a close relationship between highest aphid densities and subsequent yield loss. On one hand, an exponential model allowed them to predict the highest cereal aphid abundance from an early season population estimate, referred to here as critical threshold. The close relationship between the highest abundance and yield loss on the other hand, allows in due time, decision-making with respect to control operations. Noteworthy, a cost-efficient sampling plan is indispensable for obtaining a reliable estimate of population abundance. Particularly useful for this purpose are sequential estimations of proportions of infested sampling units with reference to a critical value (see e.g. Bianchi et al. 1989). The thresholdbased chemical control scheme can be further developed by adding additional control options, including biological and cultural control. To make efficient use of additional control factors, however, they should be viewed as complementary to and compatible with existing natural control factors including weather and host plant effects (Roux and Baumgärtner 1998).

The purpose of this work was to design a cost-efficient threshold-based chemical control strategy for $T$. urticae infesting small-scale tomato fields in central Kenya. This relies on efficient sampling plans and their use in a predictive model that should be easy to use and is done by developing a location specific model that is independent of environmental conditions. To overcome the limitations of location specificity and non-consideration of environmental parameters we evaluate a more general model that considers weather and host plant species effects on the dynamics of $T$. urticae populations. We refer to the first model as "simple" and to the second as "extended model". The extended model will serve as a basis for the future selection and integration of additional control factors such as biological, chemical and cultural control.

\section{Materials and methods}

\section{Study site and data collection in Central Kenya}

The temporal dynamics of $T$. urticae was recorded in three separate growing seasons during a period lasting from December 1999 to February 2001 at the National Fibre Crop Research Centre of the Kenya Agricultural Research Institute (KARI) at Mwea Tebere, Central Kenya. Meteorological data were recorded from a weather station located at a distance of about $150 \mathrm{~m}$ from the fields. Daily temperature averages were obtained from daily extremes measured with a minimum-maximum thermometer, while relative humidity was recorded at 15:00 h. Rainfall was recorded daily with a standard rain gauge. The daily 
temperature and relative humidity values were averaged over one-week periods yielding weekly averages of temperature and relative humidity. In the case of rainfall, the weekly sum of daily-obtained values was calculated. Tomatoes, (variety Cal-J) were raised in plastic seedling trays, brought to the field 4-5 weeks after sowing and planted at $0.6 \mathrm{~m}$ distances within the row and $0.8 \mathrm{~m}$ between the rows. The tomatoes were staked, irrigated three times a week, hand-weeded twice a month and fertilizers were applied as $400 \mathrm{~kg} / \mathrm{ha}$ of Di-Ammonium Phosphate (DAP-NPK 18:46:0) at planting and $400 \mathrm{~kg} / \mathrm{ha}$ Calcium Ammonium Nitrate $(25 \% \mathrm{~N})$ in three applications of $133 \mathrm{~kg} / \mathrm{ha} 15,30$ and 50 days after transplanting.

For sampling purposes, the fields with dimensions of approximately $20 \times 27 \mathrm{~m}$ in Season I, $20 \times 23 \mathrm{~m}$ in Season II and $19 \times 20 \mathrm{~m}$ in Season III were divided into 25 equal size strata with dimensions $4.0 \times 5.4 \mathrm{~m}$ (Season I), $4.0 \times 4.6 \mathrm{~m}$ (Season II) and $3.8 \times 4.0 \mathrm{~m}$ (Season III) to account for possible within-field heterogeneity. The within field and within plant distribution was analyzed by Sarr (2003) and a recommendation was made to limit sampling to the lower level of the plant canopy. Sarr (2003) also observed that the number of mites $(m)$ on four-leaf sampling units collected from the lower half of the plant was closely related to the number of mites $\left(m^{\prime}\right)$ per plant $\left(m^{\prime}=1.32 m+5.95 ; r^{2}=0.76 ; F=1680.24\right.$; $P<0.0001)$. This observation allowed us to neglect within-plant variability and focus on between-plant variability by maintaining the strata on field levels. In each stratum, two plants were selected at random, and mites were counted on four fully expanded leaves per plant randomly selected in the lower half of the plants. This procedure was started two weeks after transplanting and repeated ten times at weekly intervals in each crop. To also simplify the terminology, we often use between plant mean and variance instead of mean and variance on four-leaf sample units.

All sampled plants were excluded from further sampling to avoid bias inherent to the destructive sampling of four leaves. The four-leaf sample units were individually put into paper bags, stored in a cool box and taken to the laboratory, where the number of eggs, immatures (larvae, protonymphs, deutonymphs) and adult females and males, referred to as life stages, were counted using a dissecting microscope. The combined number of larvae, nymphs and adults corresponds to the number of motile life stages.

\section{Between-plant distribution}

Between-plant dispersion indices for each of the life stages were described using Taylor's power law (Taylor 1961) that we applied to the means and variances of each sample that consisted of the combined four-leaf samples taken through time. Accordingly, the mean density $(m)$ is related to the variance $s^{2}$ by $s^{2}=a m^{b}$, where $a$ is considered as a sampling factor and $b$ a species-specific constant in a given environment (Taylor 1961). The parameters were estimated by least squares linear regression of $\ln \left(s^{2}\right)$ on $\ln (m)$ for motile as well as for other life stages (eggs, immatures, males, females, total mite number).

$$
\ln \left(s^{2}\right)=\ln (a)+b \ln (m)
$$


Sampling plans for Kenyan tomato fields

\section{Enumerative sampling plan}

Equation (1) allows the design of enumerative sampling plans that are often used for studies on local population abundance in research programs. The smallest sampling size that assures the desired level of reliability is called optimum sample size (OSS). Reliability can be defined in different ways as functions of mean and variance, i.e. the first two moments (Karandinos 1976). Here, we define reliability by formal probabilistic statements and the confidence interval equal to a proportion $D$ of the mean $(m)$. The number of samples $(n)$ corresponding to the OSS is given by

$$
n=\left(\frac{z_{\alpha / 2}}{D}\right)^{2} \frac{s^{2}}{m^{2}}
$$

where $z_{\alpha / 2}$ is the upper $\alpha / 2$ point of the standard normal distribution. The substitution of $s^{2}$ by Taylor's (1961) power law yields

$$
n=\left(\frac{z_{\alpha / 2}}{D}\right)^{2} a m^{b-2}
$$

The information available allows the calculation of the OSS for all life stages defined above. Nevertheless, we limit sampling plan development to easily identifiable motile stages only.

\section{Sequential binomial sampling plan with respect to threshold}

Counting of spider mites is time consuming, especially at high densities, and therefore, agricultural practice does not readily accept enumerative sampling plans. In response, pest management specialists designed cost-efficient sequential binomial sampling (presence-absence) plans that are particularly useful when developed with respect to a critical threshold $C_{p}$ expressed as proportion of sampling units infested (Bianchi et al. 1989). Often, however, the critical proportion of infested units is not known and has to be derived from the more common critical pest density $C_{n}$.

Nachman (1984) used elements of spatial dynamics to formulate a function that relates the proportion of infested sampling units $(p)$ to mean density $(m)$ per unit.

$$
p=1-e^{\left(-\alpha^{\prime} m^{\beta^{\prime}}\right)}
$$

where $\alpha^{\prime}=\alpha /(\beta+1)$ and $\beta^{\prime}=\beta+1 ; \alpha$ and $\beta$ are species characteristic parameters in a given environment. We follow Nachman (1984) and use his procedures to estimate the parameters. Wilson et al. (1993) proposed the following binomial sampling plan, with respect to a critical proportion $C_{p}$

$$
n=\left(z_{\alpha / 2}\right)^{2}\left(p-C_{p}\right)^{-2} p(1-p)
$$

where $n$ is the number of samples to be taken if the difference between the proportion $p$ of infested sampling units and the critical proportion $C_{p}$ is set equal to the confidence interval (Karandinos 1976). Here, the reliability of the estimate is 
defined in terms of probabilistic statements, $z_{\alpha / 2}$ being the upper $\alpha / 2$ part of the standard normal distribution, and the difference $\left(p-C_{p}\right)$ is a fixed positive number (Karandinos 1976).

Equation (5) can be developed into a binomial sequential sampling plan as follows. In the sequential sampling plan under consideration here, an initial number of units (see below) is taken and additional units are considered as long as the number of infested units lies between two decision lines; once the number of infested units is outside this range a decision on an acaricide application can be taken (see Bianchi et al. 1989). The decision lines are obtained by defining a variable $x$ for the number of infested sampling units and substituting $x / n$ for $p$ in (5). After re-arranging Eq. (5), we obtain a quadratic expression for $x$; the solutions $x_{1}$ and $x_{2}$ are plotted against the sample size. In this simplified sequential sampling procedure, we follow Wilson et al. (1993) and Bianchi et al. (1989) who used one threshold $C_{p}$ and the same error rates for decision-making; moreover, we follow Pickel et al. (1983) and Bianchi et al. (1989) who, for practical reasons, accepted the probability level $P=0.9(\alpha / 2=1.65)$ and started with an initial sample size of 12 units.

Simple model on mite population build-up in Kenyan tomato fields and design of a threshold-based control strategy

In all three fields, the mite population displayed, soon after initial colonization, ageconstant structures and an exponential increase in abundance until harvest. The weather conditions at Mwea in general and temperatures in particular varied little between the three growing seasons (Fig. 1). For the $i$ th growing season, with $i=1,2,3$, an exponential model is used to express population increase through time $t$ (weeks)

$$
N_{i}(t)=N_{i}(0) e^{r_{i} t} \quad \text { or equivalently } \quad \ln \left(N_{i}(t)\right)=\ln \left(N_{i}(0)\right)+r_{i} t
$$

where $N_{i}(t)$ is the abundance at time $t, N_{i}(0)$ is the initial density at $t=0$, i.e. the time of the first sample. Using the logarithmic form of Eq. (6) we obtain estimates for $N_{i}(0)$ and $r_{i}$ via least square regression techniques. Thereafter, we evaluate a common constant rate of increase $r_{c}\left(\mathrm{week}^{-1}\right)$ for the three growing seasons according to $r_{c}=\frac{1}{3} \sum_{i} r_{i}$.

On this basis, a threshold-based control strategy can be developed in four steps. Step 1 deals with the definition of the adequate sampling date; on step 2, we make use of (6) and calculate, on the basis of literature data, the critical threshold $C_{n}$ expressed in population abundance at an adequate sampling date; on step 3 , we use (4) to express the critical threshold $C_{p}$ in proportion of infested units; on step 4 we make use of (5) to develop a sequential binomial sampling plan with respect to the critical threshold expressed as a proportion of infested units.

Extended model considering influence of weather and host plant species

\section{Extension of the database}

To explain the variability of $r_{c}$ due to both within and between growing season effects and to widen the applicability of the model beyond Central Kenyan tomato fields (data set 1), we re-formulated the intrinsic rate of increase as a function of 


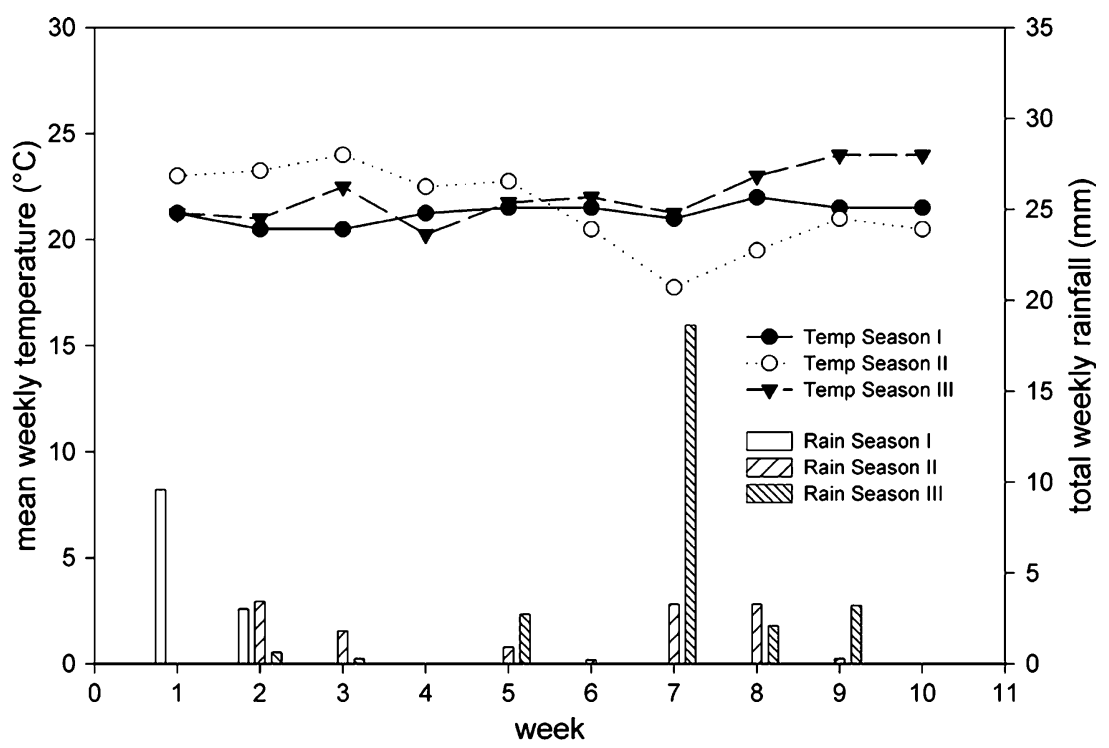

Fig. 1 Mean weekly temperature and total weekly rainfall in the three growing seasons at the field site in Mwea, Kenya

weather and host plant species. To support model development and allow reliable parameter estimation, we complement data set 1 with additional data from Californian and Italian strawberry fields (data sets 2 and 3) as well as a Swiss apple orchard data set (data set 4). The latter data set does not consist of weekly samples and hence, was not used for parameter estimation purposes. However, it was used for model testing and evaluation of effects by the apple tree host plant.

The first data set consists of mite counts in tomato fields in Mwea as described above. The second data set is obtained from an experiment on mite control carried out in 1979 in Californian strawberry fields (Marsden and Allen 1980). However, temperature and rainfall data were readily available from 1996 to 2003 only (California System Wide IPM project, http://www.ipm.ucdavis.edu/Weather/ wxretrieve.html, data kindly made available by Prof. A.P. Gutierrez, University of California, Berkeley). We used these data and calculated the 9-years daily average weather data for the period from January 1 to March 31. Later data have not been used because of natural enemy effects that we do not consider in this model. The third data set consists of $T$. urticae counts in Italian strawberry fields and was kindly made available, together with corresponding weather data, by Prof. V. Vacante, University of Reggio di Calabria, Italy and analyzed by Gilioli and Vacante (2001). Also in this case, we used the first few sample data only, because our model is not developed for biological control evaluation. The fourth data set used was obtained from Zahner and Baumgärtner $(1984,1988)$, who studied the dynamics of T. urticae populations in a Swiss apple orchard near Sion. Here, we used only the observations made from May 22 until June 6 (1979) and from May 21 until June 20 (1980), respectively. During these intervals neither natural enemies nor acaricide applications influenced mite population build-up. The weather data were obtained from MeteoSwiss, Zurich. In first approximation, we assumed constant age-structures in all data sets to satisfy an important requirement for the development of a lumped parameter model. 
Model development

The purpose was to develop a model that exclusively reflects weather and selected host plant species influences on $T$. urticae population dynamics, while other factors including biological, chemical and cultural control were excluded. Weather influences can be attributed to effects of temperature, relative humidity, rainfall and wind. Importantly, all the crops under consideration were either irrigated (data sets 1-3) or did not suffer from drought stress (data set 4). The availability of water and the absence of significant wind effects is responsible for maintaining a boundary layer around leaves in which the mites are exposed to constant high humidity (Ferro et al. 1979; Gaede 1992). Hence, the effect of humidity can be disregarded, and weather effects are restricted to temperature and rainfall only. The resulting model is

$$
r(S, T, R)=c_{1} S+c_{2} T+c_{3} R+c_{4} T R
$$

where $r($.$) is the growth rate per week of a population with exponential growth$ rate patterns, $S=$ dummy variable for plant species $(S=0$ for tomatoes, $S=1$ for strawberries), $T=$ effective weekly mean temperature above an estimated threshold of $10^{\circ} \mathrm{C}$, i.e. the 7-day average of mean daily temperatures minus the assumed threshold of $10^{\circ} \mathrm{C}, R=$ rainfall (total amount in $\mathrm{mm}$ week ${ }^{-1}$ ), and $c_{1}, c_{2}$, $c_{3}$ and $c_{4}$ are parameters to be estimated via least square regression methods. Noteworthy, the model has been developed on the basis of known effects of environmental factors and host plant species on mite dynamics.

\section{Results}

Between-plant distribution in Kenyan tomato fields and enumerative sampling plan

The relationship between mean densities on the four-leaf sample units and variance expressed by Taylor's (1961) power law was highly significant for motile stages (Fig. 2) as well as for all other life stages. The slopes were nearly identical and significantly $>1$ in all cases (Table 1 ). It appears that that the immature life stages have a lower $b$ and a higher $a$ compared to the adults.

Taylor's power law allows the design of sampling plans for all life stages sampled. For practical reasons, however, an enumerative sampling plan was designed for motile stages only because they are easier to identify and separation into life stages is time consuming. Accordingly, the number of four-leaf sample units needed for a density estimation with the reliability defined by formal probabilistic statements $(P=0.9)$ and the confidence interval equal to a proportion $(D=0.1$ and $D=0.2)$ of the mean $(m)$ was obtained. Figure 3 shows that, for densities exceeding 20 motile stages, the number of units to be sampled is about 230 and 57 for $D=0.1$ and $D=0.2$, respectively. The number of samples drops to $146(D=0.1)$ and $36(D=0.2)$ at a density of 50 mites per unit. 


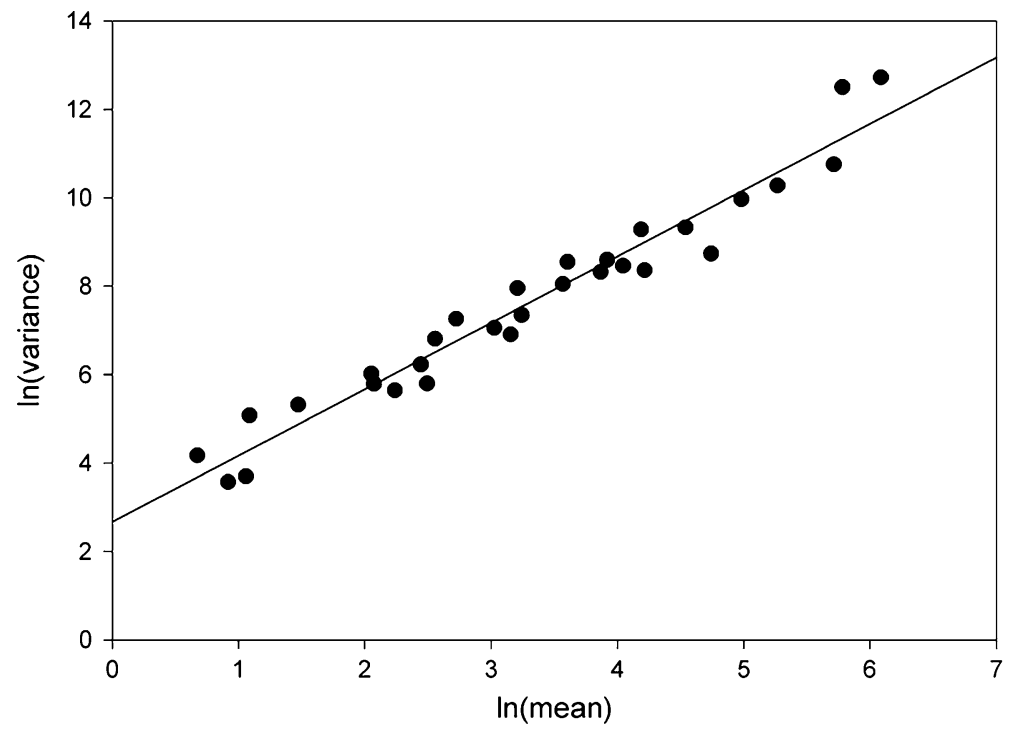

Fig. 2 Taylor's (1961) power law (Eq. 1) for describing the relationship between the variance and the mean for motile T. urticae on four-leaf samples taken on tomato plants during three growing seasons in Kenya (ten weekly samples were taken per season, the regression statistics are reported in Table 1)

Table 1 Parameter estimates of Taylor's (1961) power law (Eq. 1), with parameters $a$ and $b$ for describing the relationship between the variance and the mean for T. urticae on four-leaf samples taken on tomato plants (an $F$-test has been performed to investigate the quality of the parameter estimates, while a $t$-test confirmed the significant difference of the $b$ value from 1 at the probability level $P$ )

\begin{tabular}{llllllll}
\hline Life stage/sex & $b$ & $a$ & $F$-value* & $P>F$ & $R^{2}$ & $t$-value & $P>t$ \\
\hline All stages combined & 1.50 & 3.00 & 666.09 & $<0.0001$ & 0.96 & 25.81 & $<0.0001$ \\
Motile stages combined & 1.50 & 2.67 & 545.20 & $<0.0001$ & 0.95 & 23.35 & $<0.0001$ \\
Adult females & 1.56 & 1.76 & 359.69 & $<0.0001$ & 0.93 & 10.12 & $<0.0001$ \\
Adult males & 1.57 & 1.87 & 561.53 & $<0.0001$ & 0.95 & 23.70 & $<0.0001$ \\
Larvae and nymphs & 1.42 & 2.73 & 806.59 & $<0.0001$ & 0.97 & 28.40 & $<0.0001$ \\
Eggs & 1.50 & 2.88 & 584.06 & $<0.0001$ & 0.95 & 24.17 & $<0.0001$ \\
\hline
\end{tabular}

$* \mathrm{df}=1,28$ for all stages

Threshold-based control in Kenyan tomato fields

The results of the four-step procedure are as follows.

\section{Step 1: definition of the appropriate sampling date}

In field-grown tomatoes one treatment is usually sufficient to prevent $T$. urticae populations from reaching economically relevant densities (Bezert 1999). For deciding on a possible treatment, reliance on an early sample is advantageous for technical and logistic reasons. However, the earlier the sample the higher is the degree of uncertainty in the estimate for a given sample size. When applying sequential sampling procedures as done here, the initially high variability likely 


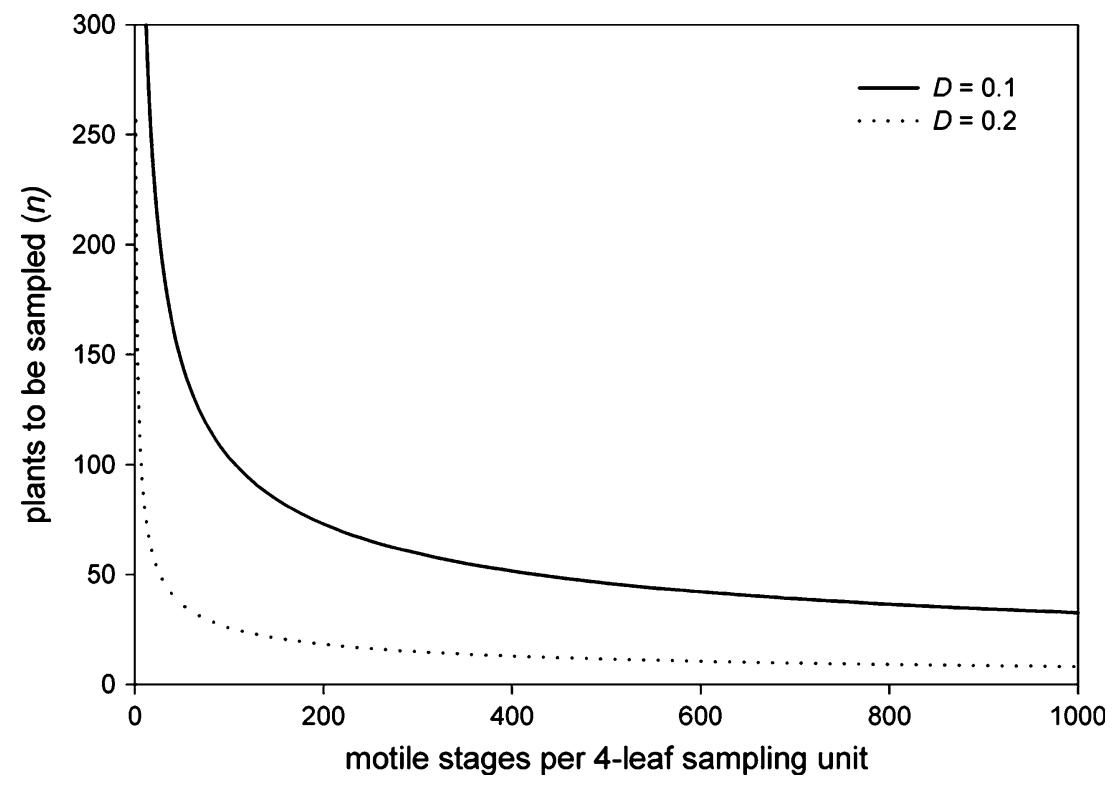

Fig. 3 Number $n$ of four-leaf samples needed to estimate the number of motile stages, at different densities, with reliability expressed by formal probabilistic statements $(\alpha / 2)$ of $1.65(P=0.9)$ and an error $(D)$ of 0.1 and 0.2 of the mean. The decision lines have been obtained by Eq. (3)

reduces the efficiency of the sampling procedure. In this work, the selection of sample 3, i.e. five weeks after transplanting, appeared to be appropriate.

Step 2: population rate of increase and calculation of the critical threshold $C_{n}$ at the appropriate sampling date

In all three seasons, the $T$. urticae populations increased slowly at the beginning and then rapidly to reach maximum densities at the last sampling date (Fig. 4). Spider mite numbers were lowest in Season I and increased in the following seasons reaching the highest densities in Season III. Equation (6) yielded a constant rate of increase of $r_{c}=0.377\left(\mathrm{df}=1,28, R^{2}=0.88, F=214.25, P<0.001\right)$ and a relative initial density of 0.0298. Sarr et al. (2002) did not find any yield reduction up to a density of 440 motile stages per four-leaf sample at the end of the sampling period (sample 10). Equation (6) allows the calculation of the critical density $C_{n}=27.92$ in sample 3 that leads to a density of 440 in sample 10, i.e. 12 weeks after transplanting.

Step 3: calculation of the critical proportion $C_{p}$ of sample units inhabited by motile mites

Nachman's (1984) model accurately described the relationship between the mean density and the proportion of infested sampling units $\left(\alpha^{\prime}=2.5015, \beta^{\prime}=1.4317\right)$ (Fig. 5) on the sampling units, the threshold of 27.92 motile stages is equivalent to a proportion of 0.83 infested units in sample 3, i.e. five weeks after transplanting (Eq. 4). 


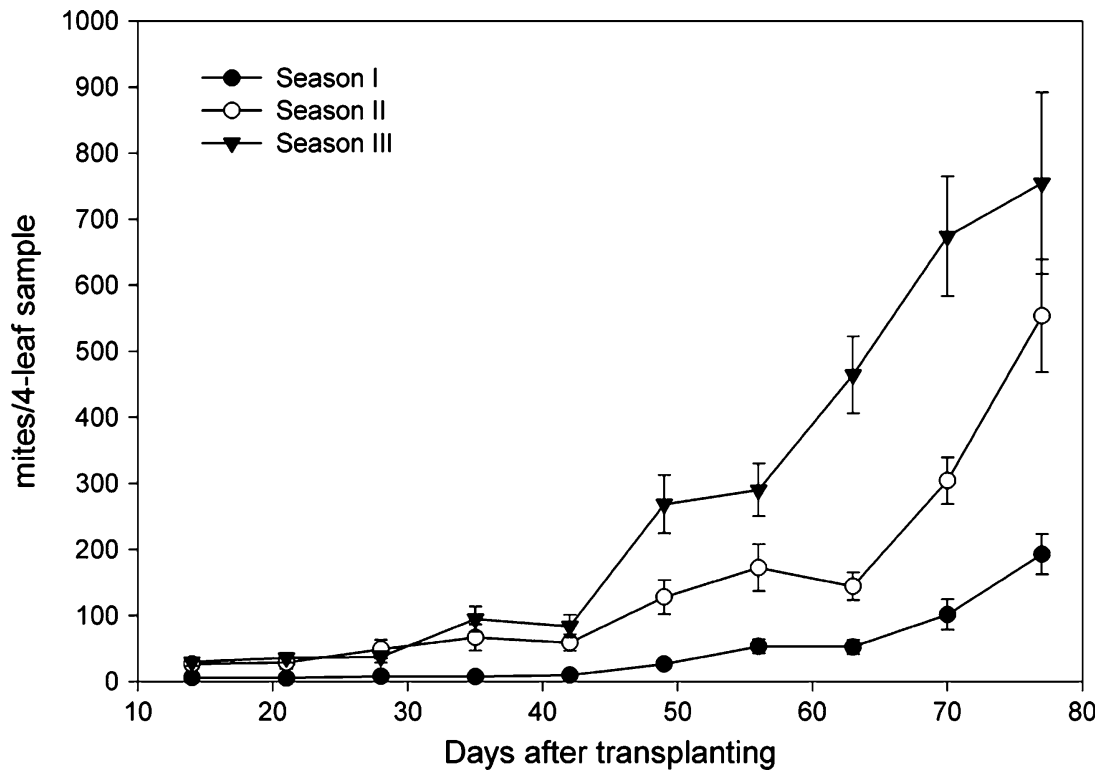

Fig. 4 Dynamics of T. urticae populations in Central Kenyan tomato fields in three different growing seasons (vertical bars indicate standard errors)

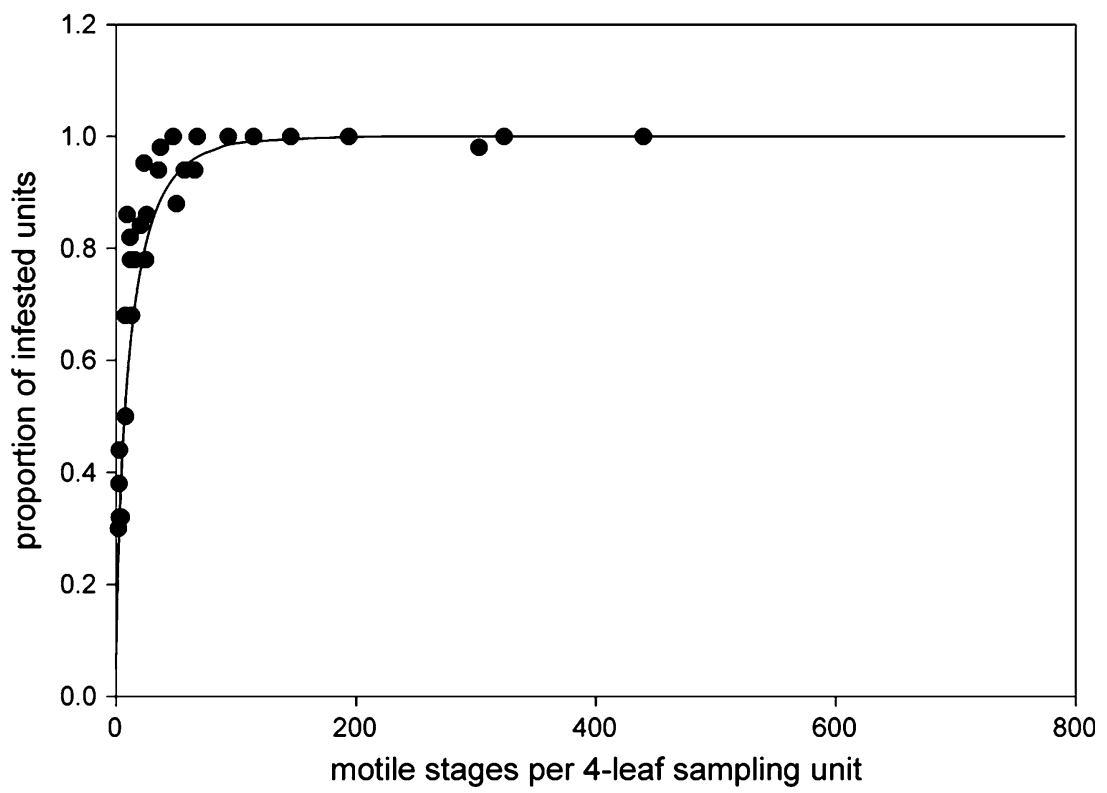

Fig. 5 Proportion of occupied four-leaf sample units as a function of the mean number of motile T. urticae per sample unit derived from Nachman's (1984) model (Eq. 4)

\section{Step 4: calculation of decision lines for binomial sequential sampling}

According to (5), the decision lines can be calculated and represented in Fig. 6. Starting with an initial sampling size of 12 sample units the number of infested plants 


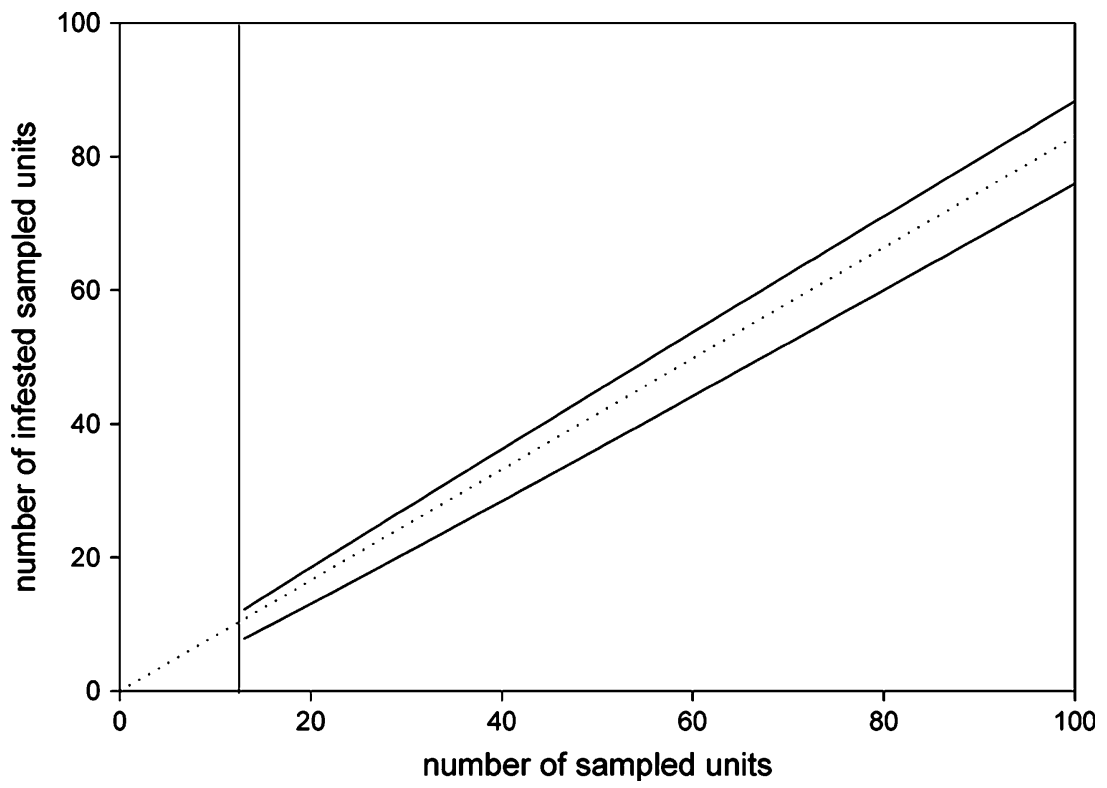

Fig. 6 Decision lines for sequential sampling of the proportion of four-leaf units occupied by motile T. urticae life stages, relative to the critical proportion of 0.83 occupied units taken 5 weeks after transplanting. The decision lines have been obtained on the basis of Eq. (5). Starting with an initial sample size of 12 units (represented by the vertical line), the number of occupied units is counted; if the resulting number is inside the range delimited by the decision lines, additional samples are taken until the resulting number is outside the range and a decision can be taken

is added up. If the number of infested plants falls within the confidence lines new plants are sampled until a decision can be made.

Influence of weather and host plant species on temporal population dynamics

Table 2 shows that the weekly rate of population increase $(r)$ is significantly influenced by plant species, rainfall and temperature as well as by the interaction between rainfall and temperature. The $R^{2}=0.6$ indicates that the model satisfactorily describes the dependency of $r$ on weather and host plant species under consideration and confirms the validity of the relationships integrated into the model.

Table 2 Regression statistics for the weekly rate $(r)$ of $T$. urticae population increase depending on effective temperature (weekly mean temperature minus the estimated threshold of $10^{\circ} \mathrm{C}$ ), plant species (tomato vs. strawberry), rainfall, and interaction between rainfall and temperature (S.E.M. = standard error of the mean)

\begin{tabular}{|c|c|c|c|c|}
\hline Independent variables & $R^{2}$ & $F$-value & Slope & S.E.M. \\
\hline & 0.60 & $21.38 *$ & & \\
\hline Effective temperature $(T)$ & & & 0.03378 & 0.00871 \\
\hline Plant species $(S)$ & & & 0.53316 & 0.09997 \\
\hline Rainfall $(R)$ & & & -0.02080 & 0.01608 \\
\hline Rain $\times$ Temperature $(R \times T)$ & & & 0.00130 & 0.00291 \\
\hline
\end{tabular}

$* P<0.0001$ 


\section{Discussion}

The close relationship between the four-leaf sample taken in the lower plant part and the total density per plant allowed us to disregard within-plant distributions and focus on between-plant distribution. Noteworthy, the spider mite populations were not affected by significant effects of biological control. In case of significant natural enemy activity, however, we expect a different spatial distribution that may require revision of the proposed sampling plans.

The coefficients of Taylor's (1961) power law indicated an aggregated distribution for all life stages as has been observed in other studies (see e.g. Zahner and Baumgärtner 1984; Wilson and Morton 1993; Opit et al. 2003). The value for the slope obtained in our studies is very close to the generic value reported for T. urticae by Jones (1990) who used bootstrap estimates to analyze T. urticae distribution data derived under many different conditions. However, caution is advised when making comparisons with published data obtained by using different methods including varying unit size. Baumgärtner et al. (2002) studied the relevant literature and discussed the effect of an increase in the physical sample size on the variance leading to different coefficients for Taylor's (1961) power law. Sampling units of different sizes detect different spatial distributions, and the above interpretation of Taylor's (1961) power law parameters depends on the sampling methodology. Moreover, Baumgärtner et al. (2002) referred to work indicating that an increase in field dimensions may affect the factor $a$.

The enumerative sampling plan (Fig. 3) necessitates high numbers of four-leaf sample units to be sampled. It may provide detailed data on population structures in a research program aiming at explaining population dynamics including changes in population structures at low densities. However, it is too labor-intensive for monitoring in threshold-based pest control, where a sequential binomial sampling plan with respect to a threshold is easier to use and more cost-efficient. Nyrop et al. (1989) compared sequential sampling procedures for Panonychus ulmi (Koch) based on complete counts and binomial sampling and found that the average number of samples needed and precision, expressed as probability to incorrectly classify the population with respect to the threshold, was almost the same but the binomial procedure can be much more rapidly executed in the field.

In small-scale farmers' tomato fields in Kenya, population densities can be estimated with an exponential model. The rate of increase $r_{c}=0.377$ week $^{-1}$ is equivalent to 0.054 day $^{-1}$ at an average sample mean temperature of $21.6^{\circ} \mathrm{C}$, i.e. averaged over all three growing seasons. This is within the range of intrinsic rate of natural increase values $\left(0.03-0.10 \mathrm{day}^{-1}\right)$ reported from laboratory studies with T. urticae on tomatoes but these studies were done at slightly higher temperatures of 24-25 ${ }^{\circ} \mathrm{C}$ (Van Impe and Hance 1993; Witul and Kielkewicz 1999; Castagnoli et al. 2003). These rates, however, are lower than the values obtained on apple where Wermelinger et al. (1990) reported 0.20 at $21^{\circ} \mathrm{C}$, Herbert (1981) 0.372 at $21^{\circ} \mathrm{C}$ and Pringle et al. (1994) 0.128 and 0.187 at $24^{\circ} \mathrm{C}$ for two different strains of T. urticae. Laing (1969) reported an $r$ value of 0.143 on strawberry at $20.3^{\circ} \mathrm{C}$ while Van Impe and Hance (1993) measured 0.104 and 0.087 at $24^{\circ} \mathrm{C}$ for two different strawberry varieties. Also on strawberries, Buffoni and Gilioli (2003) obtained similar values through an analysis of experimental data referring to the individual level. These laboratory values vary widely due to experimental conditions and strain differences 


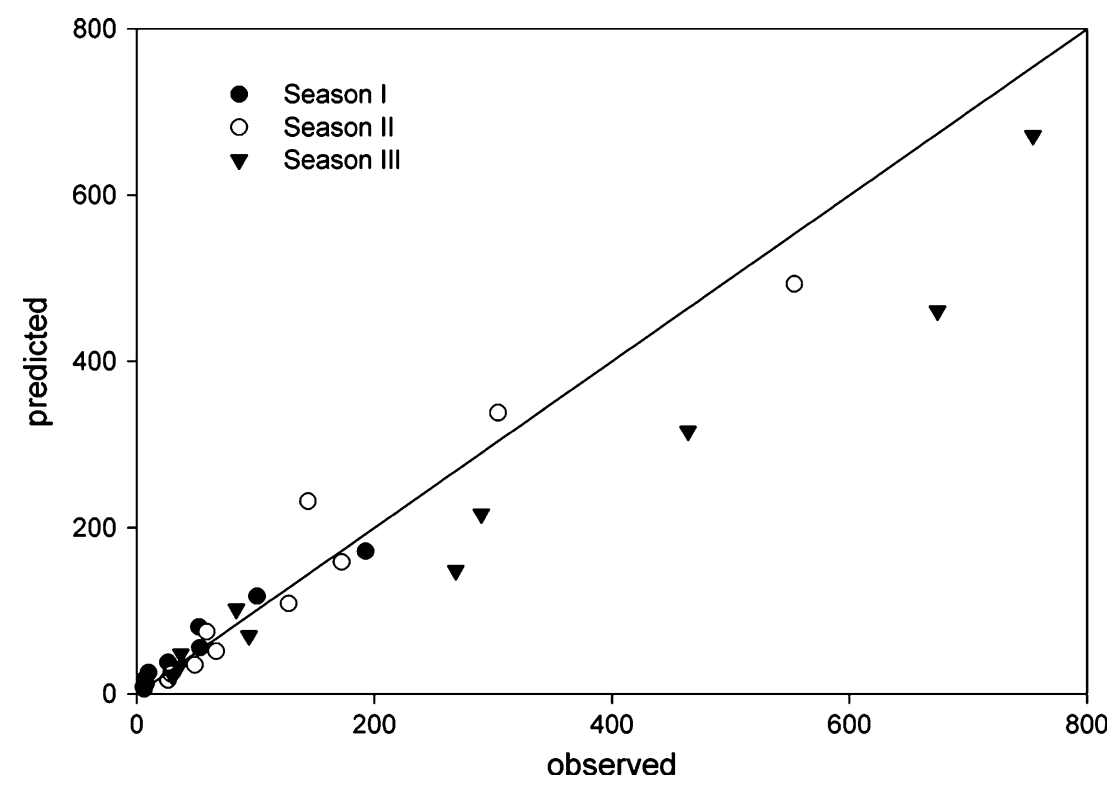

Fig. 7 Observed versus predicted densities of $T$. urticae populations in Kenyan tomato fields during three growing seasons. The predictions have been obtained by the model given in Eq. (6) with a common rate of increase

and are difficult to compare with our field data but generally, it seems that apples and strawberries are more favorable host plants for $T$. urticae than tomatoes.

Figure 7 shows the relationship between predicted (6) and observed densities. Presumably, some disagreements result from the inability of the exponential model to take into account the long initial phase preceding the exponential phase in the second phase of the infestation (Fig. 4). In addition, the growth pattern in growing Season III appears to slightly differ from Seasons I and II (Fig. 4). This difference may also explain some disagreements between observed and predicted densities in Fig. 7. This shows the limitations of using a simple model and justifies the development of an extended model that considers environmental and host plant factors.

Our reliance on Sarr et al. (2002) who did not find any yield reduction up to a density of 440 mobile stages per four-leaf sample leads to a threshold that we consider as conservative because the real threshold may be higher but there are no data available to define it. Bezert (1999) reported yields of $75,000 \mathrm{~kg} \mathrm{ha}^{-1}$ and peak densities of 20 motile $T$. urticae per leaflet in tomatoes treated with acaricides once at early infestation compared to $55,000 \mathrm{~kg} \mathrm{ha}^{-1}$ and peak densities of 38 motile mites per leaflet in the control. However, a comparison between these studies is difficult since the sampling units are different, therefore we rely on Sarr et al. (2002) to define our threshold. In our view, the use of one treatment with respect to a conservative threshold is an improvement of the current chemical pest control strategy relying on routine calendar spraying that can further be rationalized if additional experiments permit the use of a higher threshold than the one used here.

The parameter values of the extended model (7) reported in Table 2 and partial derivatives allow the assessment of the relative importance of weather and host plants on $T$. urticae population growth rates. 


$$
\begin{aligned}
& \frac{\partial r}{\partial S}=c_{1} \\
& \frac{\partial r}{\partial T}=c_{2}+c_{4} R \\
& \frac{\partial r}{\partial R}=c_{3}+c_{4} T
\end{aligned}
$$

Accordingly, the change from tomato to strawberry host plants increases the growth rate by 0.533 (Table 2, Eq. (8a)). In absence of any rainfall, an increase by $1^{\circ} \mathrm{C}$ increases the growth rate by 0.034 (Table 2), while Wermelinger et al. (1990) reported a much lower value (0.014). Noteworthy, our growth rate also takes into account migration while the studies by Wermelinger et al. (1990) have been conducted in the laboratory allowing only restricted movements to mites. Under average sample values for rain, $R=3.12 \mathrm{~mm}^{\text {week }}{ }^{-1}$, an increase in temperature by $1^{\circ} \mathrm{C}$ augments the growth rate by 0.0744 . Under average sample values for temperature, $T=21.6^{\circ} \mathrm{C}$, an additional unit of rainfall increases the growth rate by 0.00728 . To evaluate temperature and rainfall, the interactions leading to thresholds, i.e. values at which changes in values of independent variables result to a change in the direction of the response, have to be considered. For example, the temperature effect is negative if rainfall exceeds $1.6 \mathrm{~mm}^{\text {week }}{ }^{-1}$ and positive otherwise. On the other hand, the rainfall effect is positive above $15.4^{\circ} \mathrm{C}$ and negative otherwise. The existence of thresholds might be supported by the literature. Van de Vrie et al. (1972), Simpson and Connell (1973), Yaninek et al. (1989) and Wermelinger et al. (1992) observed a significant impact of rainfall, while Klubertanz et al. (1990) and Skovgård et al. (1993) found no effect. The actual threshold values, however, are probably not reliable for a detailed discussion. This is first because the temperature range for all fields was between $11.6^{\circ} \mathrm{C}$ and $23.3^{\circ} \mathrm{C}$, i.e. clearly within the lower range of temperatures permitting the development of $T$. urticae. In fact, development is possible up to a threshold of $35^{\circ} \mathrm{C}$ (Gutierrez 1976). Likewise, the range of rainfall $\left(0-23.5 \mathrm{~mm}\right.$ week $\left.^{-1}\right)$ is low compared to the rainfall values reported in other studies examining the influence of rain on mite population growth (Yaninek et al. 1989; Wermelinger et al. 1992). We assume that reliance on a restricted data set contributed to unreliable parameter estimates resulting to limited predictability of responses by the regression model.

The model has been developed for field strawberry and field tomato host plants and can be used for predicting the growth rate of apple tree inhabiting T. urticae populations. As expected, the model predicts a slow population build-up due to the low spring temperatures in Swiss apple orchards ranging from $11.9^{\circ} \mathrm{C}$ to $19.0^{\circ} \mathrm{C}$. In 1979, the mite population development was similar to the one predicted for strawberry host plants; in 1980, however, population development was closer to the one predicted for tomatoes than strawberries. We infer from these results that the suitability of host plants increases from tomatoes over apple trees to strawberries.

The regression model provides some insight into the dynamics of unstructured T. urticae populations exposed to host plant and weather influences and thus, is considered to be a starting point for the development of a model in which the assumption of constant age-structures would possibly be relaxed and additional driving variables including naturally occurring biological control would be built-in. Noteworthy, biological control had an insignificant effect on spider mite populations 
in Kenyan tomato fields (Sarr et al. 2002). This has also been observed in Southern France (Bezert 1999) and raises questions about the effectiveness of natural enemies of T. urticae in tomato crops. In greenhouses, it has been shown that Phytoseiulus persimilis Athias-Henriot is hindered by the trichomes of tomato plants (Nihoul 1993b). However, these results should not lead to underestimation of biological control that has been an important factor in spider mite population systems and has been successfully applied in many crops (Helle and Sabelis 1985). Such a model would allow the evaluation of control options including chemical, biological and cultural control on population structures. These features would make it a more useful tool in the design of an IPM program than the regression model presented here.

IPM schemes have been developed at various levels in temporal, spatial, biological and organizational hierarchies (Kogan et al. 1999; Baumgärtner et al. 2003). To address the problems of small-scale tomato growers, however, we initially focused on field-specific dynamics of $T$. urticae populations during the growing seasons of tomato crops. We recognize the importance of the spatial and temporal arrangement of tomato fields within the cropping system and the possibilities for using it in IPM system design and implementation, but limited resources do not allow the consideration of these aspects in this work. We are also aware of the presence of other arthropod pests than T. urticae (e.g. Helicoverpa armigera (Hübner), Sithanantham et al. (2001)), but the establishment of a crop-specific rather than a pest-specific IPM scheme also goes beyond the purpose of this work.

Acknowledgements Prof. V. Vacante, University of Reggio di Calabria, Italy, kindly made available data on T. urticae fluctuations in Italian strawberry fields and provided the weather data for the period under study. Prof. A.P. Gutierrez, University of California, Berkeley, USA, made available the San Jose weather data from the California System Wide IPM Project. The Federal Office of Meteorology and Climatology (MeteoSwiss), Zurich, Switzerland, provided the weather data for Sion. This study was funded by a grant of the German Federal Ministry of Economic Cooperation and Development (BMZ) to ICIPE.

\section{References}

Abdel-Shaheed GA, Abdel-Salam AM, Assem MA (1971) Experimental studies on tomato pests. II. Effects of mites on tomato yield and fruit quality. J Appl Entomol 69:402-406

Baumgärtner J, Gutierrez AP, Klay A (1988) Elements of modelling the dynamics of tritrophic population interactions. Exp Appl Acarol 5:243-263

Baumgärtner J, Gilioli G, Schneider D, Severini M (2002) The management of populations in hierarchically organized systems. Notiz Prot Piante 15:247-263

Baumgärtner J, Schulthess F, Xia YL (2003) Integrated arthropod pest management systems for human health improvement in Africa. Insect Sci Appl 23:85-98

Bezert J (1999) Tetranychus urticae on processing tomatoes. How to reason cultural practices? Acta Hort 487:257-261

Bianchi G, Baumgärtner J, Delucchi V, Rahalivavololona N, Skillman S, Zahner P (1989) Sampling egg batches of Maliarpha separatella Rag. (Lep. Pyralidae) in Madagascan rice fields. Trop Pest Manage 35:420-424

Buffoni G, Gilioli G (2003) A lumped parameter model for acarine predator-prey population interactions. Ecol Model 170:155-171

Castagnoli M, Caccia R, Liguori M, Simoni S, Marinari S, Soressi GP (2003) Tomato transgenic lines and Tetranychus urticae: changes in plant suitability and susceptibility. Exp Appl Acarol 31:177-189

Daiber KC (1996) Injurious insects, spider mites and nematodes on tomatoes in southern Africa. Z Pflkrankh Pflschutz 103:94-110

Springer 
Ferro DN, Chapman RB, Penman DR (1979) Observations on insect microclimate and insect pest management. Environ Entomol 8:1000-1003

Gaede K (1992) On the water balance of Phytoseiulus persimilis and its significance. Exp Appl Acarol 15:181-198

Gilioli G, Vacante V (2001) Aspetti della dinamica di popolazione del sistema Tetranychus urticaePhytoseiulus persimilis in pieno campo: implicazioni per le strategie di lotta biologica. Notiz Prot Piante 13:95-99

Gutierrez J (1976) Etude biologique et écologique de Tetranychus neocaledonicus André (Acarien, Tetranychidae). Travaux et Documents de l'ORSTOM. ORSTOM, Paris

Gutierrez AP (1996) Population ecology. A supply-demand approach. Wiley, New York

Helle W, Sabelis MW (eds) (1985) Spider mites, their biology, natural enemies and control, vol 1B. Elsevier, Amsterdam

Herbert HJ (1981) Biology, life tables, and innate capacity for increase of the twospotted spider mite, Tetranychus urticae (Acarina, Tetranychidae). Can Entomol 113:371-378

Hussey NW, Scopes NEA (1985) Greenhouse vegetables (Britain). In: Helle W, Sabelis MW (eds) Spider mites, their biology, natural enemies and control, vol 1B. Elsevier, Amsterdam, pp 285-297

Jensen A, Mingochi DS (1988) Chemical control of red spider mite (Tetranychus urticae Koch) on tomatoes in Zambia. Acta Hort 218:275-280

Jones VP (1990) Developing sampling plans for spider mites (Acari: Tetranychidae): those who don't remember the past may have to repeat it. J Econ Entomol 83:1656-1664

Kapatos ET, Stratopoulou ET (1990) Population dynamics of Saissetia oleae. II. Life-tables and key-factor analysis. Entomol Hell 8:59-64

Karandinos MG (1976) Optimum sample size and comments on some published formulae. Bull Entomol Soc Am 22:417-421

Kielkiewicz M (1996) Dispersal of Tetranychus cinnabarinus on various tomato cultivars. Entomol Exp Appl 80:254-257

Klubertanz TH, Pedigo LP, Carlson RE (1990) Effects of plant moisture stress and rainfall on population dynamics of the twospotted spider mite (Acari: Tetranychidae). Environ Entomol 19:1773-1779

Kogan M, Croft BA, Sutherst RF (1999) Applications of ecology for integrated pest management. In: Huffacker CB, Gutierrez AP (eds) Ecological entomology, 2nd edn. Wiley, New York, pp 681-736

Laing JE (1969) Life history and life table of Tetranychus urticae Koch. Acarologia 11:32-42

Marsden DA, Allen WW (1980) Evaluation of two selective acaricides on strawberries for control of the twospotted spider mite and their effect on the predatory mite, Metaseiulus occidentalis. J Econ Entomol 73:168-171

Nachman G (1984) Estimates of mean population density and spatial distribution of Tetranychus urticae (Acarina: Tetranychidae) and Phytoseiulus persimilis (Acarina: Phytoseiidae) based upon the proportion of empty sampling units. J Appl Ecol 21:903-913

Nihoul P (1993a) Spatial distribution of spider mites and predatory mites on the plant related to biological control effectiveness on glasshouse tomatoes. Med Fac Landbouww Univ Gent 58:497-505

Nihoul P (1993b) Do light intensity, temperature and photoperiod affect the entrapment of mites on glandular hairs of cultivated tomatoes? Exp Appl Acarol 17:709-718

Nihoul P, van Impe G, Hance T (1991) Characterizing indices of damage to tomato by the two-spotted spider mite Tetranychus urticae Koch (Acari; Tetranychidae) to achieve biological control. J Hort Sci 66:643-648

Nyrop JP, Agnello AM, Kovach J, Reissig WH (1989) Binomial sequential classification sampling plans for European red mite (Acari: Tetranychidae) with special reference to performance criteria. J Econ Entomol 82:482-490

Opit GP, Margolies DC, Nechols JR (2003) Within-plant distribution of twospotted spider mite, Tetranychus urticae Koch (Acari: Tetranychidae) on ivy geranium: Development of a presenceabsence sampling plan. J Econ Entomol 96:482-488

Pickel C, Mount RC, Zalom FG, Wilson LT (1983) Monitoring aphids on Brussels sprouts. Calif Agric 37:24-25

Pringle KL, Drayton AW, Northcraft PPD (1994) Development biology of the carmine and green forms of Tetranychus urticae Koch (Acarina: Tetranychidae). Afr Entomol 2:127-132

Rabbinge R, Rijsdijk FH (1983) EPIPRE: a disease and pest management system for winter wheat, taking account of micrometeorological factors. EPPO Bull 13:297-305 
Roux O, Baumgärtner J (1998) Evaluation of mortality factors and risk analysis for the design of an integrated pest management system. Ecol Model 109:61-75

Sarr I (2003) Bioecology and population dynamics of spider mites (Acari: Tetranychidae on tomato in small scale production systems in Kenya. PhD thesis, Kenyatta University, Nairobi, Kenya

Sarr I, Knapp M, Ogol CPKO, Baumgärtner J (2002) Predatory effects on spider mite populations and their damage on tomatoes. In: Tenywa JS, Nampala MP, Kyamanywa S, Osiru M (eds) Integrated pest management conference proceedings, Kampala, pp 1-9

Sibanda T, Dobson HM, Cooper JF, Manyangarirwa W, Chiimba W (2000) Pest management challenges for smallholder vegetable farmers in Zimbabwe. Crop Prot 19:807-815

Simpson KW, Connell WA (1973) Mites on soybeans: moisture and temperature relations. Environ Entomol 2:319-323

Sithanantham S, Abera TH, Baumgärtner J, Hassan SA, Löhr B, Monje JC, Overholt WA, Paul AVN, Hao Wan F, Zebitz CPW (2001) Egg parasitoids for augmentive biological control of lepidopteran vegetable pests in Africa: research status and needs. Insect Sci Appl 21:189-205

Skovgård H, Tomkiewicz J, Nachman G, Münster-Swendsen M (1993) The dynamics of the cassava green mite Mononychellus tanajoa in a seasonally dry area in Kenya. Exp Appl Acarol 17:59-76

Stacey DL, Wyatt IJ, Chambers RJ (1985) The effect of glasshouse red spider mite on the yield of tomatoes. J Hort Sci 60:517-523

Taylor LR (1961) Aggregation, variance and the mean. Nature 189:731-735

Van de Vrie M, McMurtry JA, Huffacker CB (1972) Ecology of tetranychid mites and their natural enemies: a review. III. Biology, ecology, and pest status, and host-plant relations of tetranychids. Hilgardia 41:343-432

Van Impe G, Hance T (1993). Une technique d'évaluation de la sensibilité variétale au tétranychidae tisserand, Tetranychus urticae Koch (Acari: Tetranychidae). Application au haricot, au concombre, à la tomate et au fraisier. Agronomie 13:739-749

Varela AM, Seif A, Löhr B (2003) A guide to IPM in tomato production in Eastern and Southern Africa. ICIPE Science Press, Nairobi

Wermelinger B, Baumgärtner J, Zahner P, Delucchi V (1990) Environmental factors affecting life tables of Tetranychus urticae Koch (Acarina). I. Temperature. Mitt Schweiz Ent Ges 63:55-62

Wermelinger B, Candolfi MP, Baumgärtner J (1992) A model of the European red mite (Acari, Tetranychidae) population dynamics and its linkage to grapevine growth and development. J Appl Entomol 114:155-166

Wilson LJ, Morton R (1993) Seasonal abundance and distribution of Tetranychus urticae Koch (Acari: Tetranychidae), the two-spotted spider mite, on cotton in Australia and implications for management. Bull Entomol Res 83:291-303

Wilson LT, Pickel C, Mount RC, Zalom FG (1993) Presence-absence sequential sampling for cabbage aphid and green peach aphid (Homoptera: Aphididae) on Brussels sprouts. J Econ Entomol 76:476-479

Witul A, Kielkiewicz M (1999) Life-history parameters of two closely related forms of the Tetranychus urticae-complex on different host plants. In: Bruin J, van der Geest LPS, Sabelis MW (eds) Ecology and evolution of the Acari. Kluwer, Dorderecht, pp 399-404

Yaninek JS, Herren HR, Gutierrez AP (1989) Dynamics of Mononychellus tanajoa (Acari: Tetranychidae) in Africa: seasonal factors affecting phenology and abundance. Environ Entomol 18:625-632

Zahner P, Baumgärtner J (1984) Sampling statistics for Panonychus ulmi Koch (Acarina: Tetranychidae) and Tetranychus urticae Koch (Acarina: Tetranychidae) feeding on apple trees. Res Popul Ecol 26:97-112

Zahner P, Baumgärtner J (1988) Analyse des interactions plante-tétranyques-phytoséiides. I. Modèles de population pour la dynamique de Panonychus ulmi et Tetranychus urticae en vergers de pommier. Acta Oecol Oecol Appl 9:311-331 